Obada B ${ }^{2}$, Serban Al. O. ${ }^{1}$, Turcu R. ${ }^{1}$

\title{
The Role of the Radiological Parameters in the Diagnosis of the Ankle Joint Fractures
}

${ }^{1}$ Clinic of Orthopedics and Traumatology, Emergency County Hospital Constanta

${ }^{2}$ Faculty of Medicine, "Ovidius" University of Constanta, Romania

\begin{abstract}
The ankle stability and its biomechanics can be compromised after ligamentous and malleolus lesions. The complete early diagnosis, and also the early and late postsurgery results, must be formulated and explained using the tibio-astragalus radiologic indices. The paper evaluates the importance of these presurgery and postsurgery indices, analyzing also the late results under causal report. Our subordinating to the exigency of radiologic indices to obtain a reparation as anatomic as possible, shows that the surgical treatment must be applied to osteo-ligamentous lesions properly, so that to get the remake of tibio-astragalus biomechanics.
\end{abstract}

Keywords: ankle, malleolus, fracture, radiology

\section{Obada Bogdan}

Constanta, Romania;

bogdanobada@yahoo.com

\section{Introduction}

Considered as the most common articular fractures, the malleolar fractures compromise the ankle biomechanic, being an important cause of the tibio-astragalus arthrosis. The traumatism can affect the joint due to osteo-ligamentous lesions, which must be treated, respecting the anathomical parameters which can be evaluate using the radiological parameters [1,2].

The malleolar fractures and the associated ligamentous lesions can modify the joint by affecting the biomechanical function, resulting as consequence the necessity of a complex dyagnosis and an adecvate therapeutical solution [3].

We propose to analyse the importance of the tibio-astraglian radiological parameters, in concordance with the initially dyagnosis, the therapeutical possibilities and the late results. 
1. The casuistry is formed by 2 groups of patients. The first group contains 225 malleolar fractures, hospitalized and operated, and the second group contains 87 cases after 1 year from surgery (aleatory group).

2. The initial diagnosis and the postsurgical evaluation were formulated using the radiological parameters from the standard x-rays (two incidence). For the antero-posterior incidence we used Wangermans position (internal rotation of the ankle $30^{\circ}$ ) [4], to show the inferior tibio-fibular joint, but was not correctly made in all the cases. following:

The radiological parameters we used were the

- Skinner test - the congruency of astragalus

- The value of the internal tibio-astragalian space - internal tibio-astragalian distasis

- Inferior tibio-fibular raport - inferior tibioperonier diastasis

- Tibio-astragalian angle

- Bimaleolo-tibial angle - the shortening of the peroneus malleolus

- Measurement of fracture displacement

- Radiological parameters of ankle arthrosis - narrowing of the articular space, underchondral osteosclerosis, malleolar osteophytosis. (Figure 1)

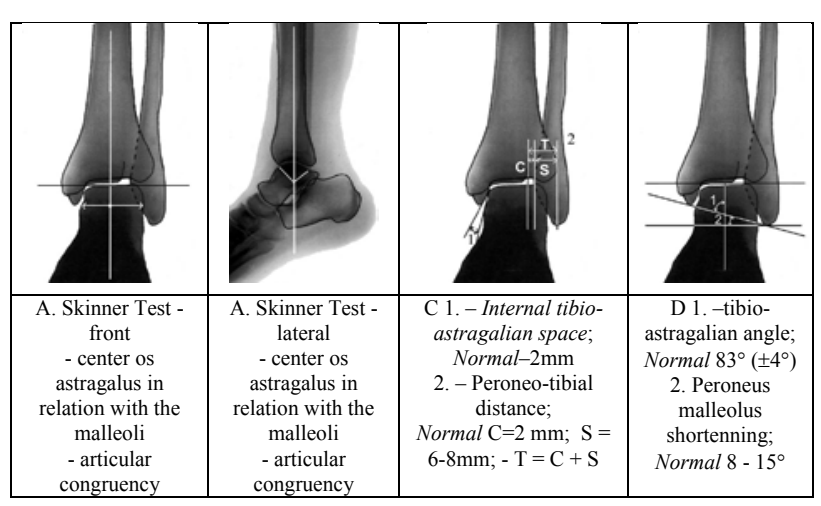

Figure1 - Normal radiological parameters
Osteo-ligamentary lesion mechanism was evaluated through clinical and radiological examination, systematizing the first group based upon the Lauge-Hansen classification [5]. (Table I), (Figures 2 and 3), (Table II), (Figures 4 and 5), (Table III), (Figures 6 and 7), (Table IV), (Figures 8 and 9), (Table V), (Figure 10)

Table II

\begin{tabular}{|c|c|c|}
\hline \multicolumn{2}{|c|}{ B. Fractures by supination-adduction } \\
\hline I & $\begin{array}{c}\text { Peroneus malleolus fracture, tear of anterior tibio-peronier } \\
\text { ligament }\end{array}$ & 26 \\
\hline II & Tibial malleolus fracture & 1 \\
\hline \multicolumn{2}{|c|}{ Total } & 27 \\
\hline
\end{tabular}

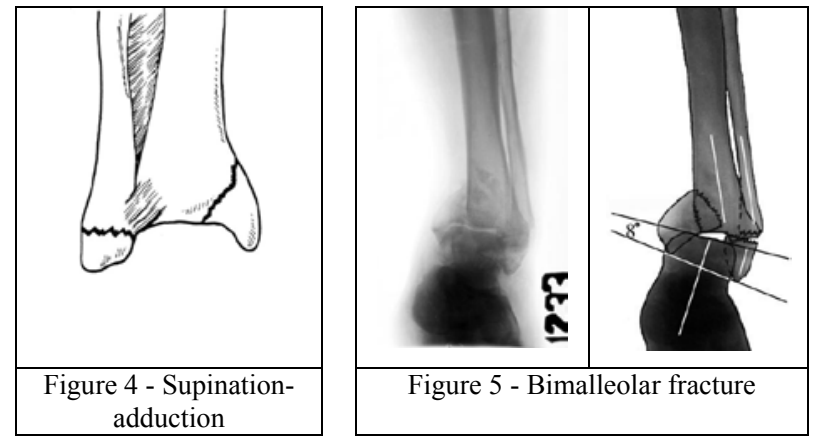

Table III

\begin{tabular}{|c|c|c|}
\hline \multicolumn{3}{|c|}{ C. Fractures by pronation-external rotation } \\
\hline I & Tibial malleolus fracture or tear of deltoid ligament & 7 \\
\hline II & Tear of anterior tibio-peronier ligament & 0 \\
\hline III & Peroneus malleolus fracture & 73 \\
\hline IV & $\begin{array}{c}\text { Posterior marginal fracture or tear of posterior tibio-peronier } \\
\text { ligament }\end{array}$ & 23 \\
\hline \multicolumn{2}{|c|}{ Total } & 103 \\
\hline
\end{tabular}
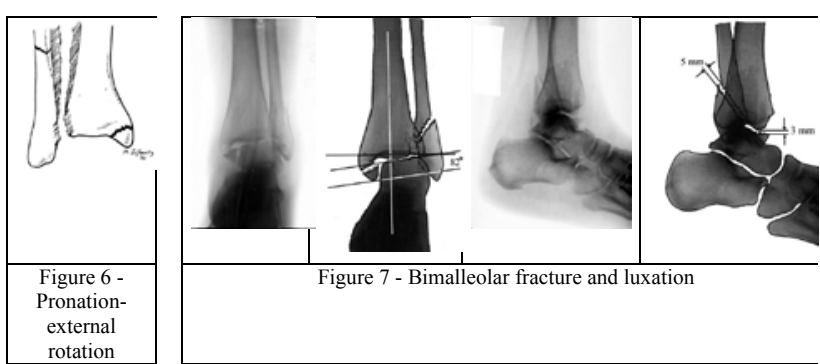
Table IV

\begin{tabular}{|c|c|c|}
\hline \multicolumn{3}{|c|}{ D. Fractures by abduction (pronation-abduction) } \\
\hline I & Tibial malleolus fracture or tear of deltoid ligament & 2 \\
\hline II & Posterior marginal fracture or tear of both tibio-peronier ligament & 2 \\
\hline III & Peroneus malleolus fracture & 33 \\
\hline \multicolumn{2}{|c|}{ Total } & 37 \\
\hline
\end{tabular}
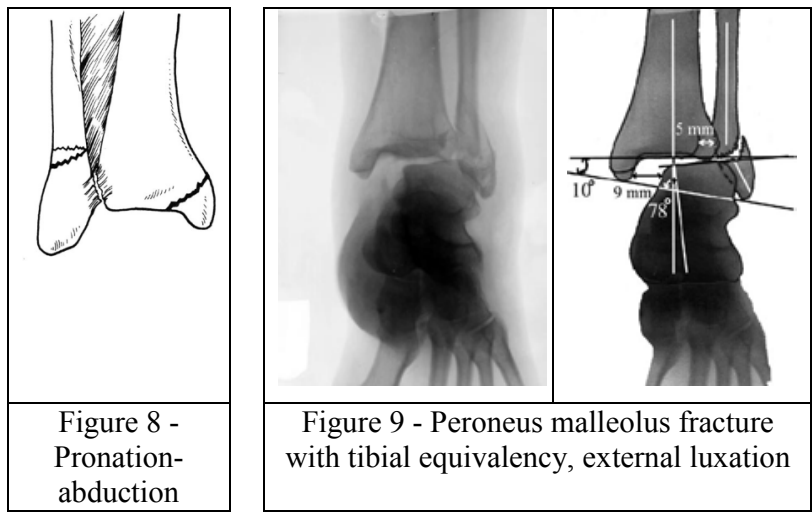

Table $V$

\begin{tabular}{|c|c|c|}
\hline \multicolumn{3}{|c|}{ E. Fractures by pronation-dorsiflexion } \\
\hline I & Tibial malleolus fracture or tear of deltoid ligament & 0 \\
\hline II & Anterior marginal fracture & 2 \\
\hline III & Peroneus fracture & 0 \\
\hline IV & Posterior marginal fracture & 0 \\
\hline \multicolumn{2}{|c|}{ Total } & 2 \\
\hline
\end{tabular}

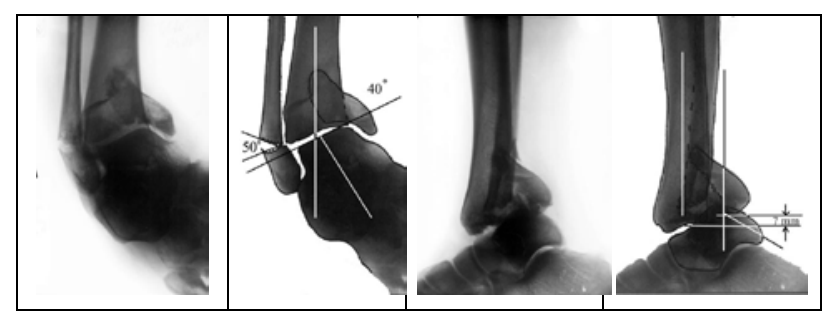

Figure 10 - Bimaleolllar and posterior marginal fracture with posterior luxation of astragalus

After 12 months from the surgery, the results were evaluated using the same radiological parameters. The abnormal values of these parameters were clinically analyzed as late complications, which take in discussion the precision of the first diagnosis and the treatment of the lesions. (Table VI), (Figures $11,12,13$ and 14)
Tale VI

\begin{tabular}{|c|c|c|}
\hline Result & No & \% \\
\hline Normal consolidation & 45 & 51,7 \\
\hline Normal consolidation with incipent arthrosis & 8 & 9,2 \\
\hline Arthrosis risk & 22 & 25,3 \\
\hline Arthrosis & 12 & 13,8 \\
\hline
\end{tabular}
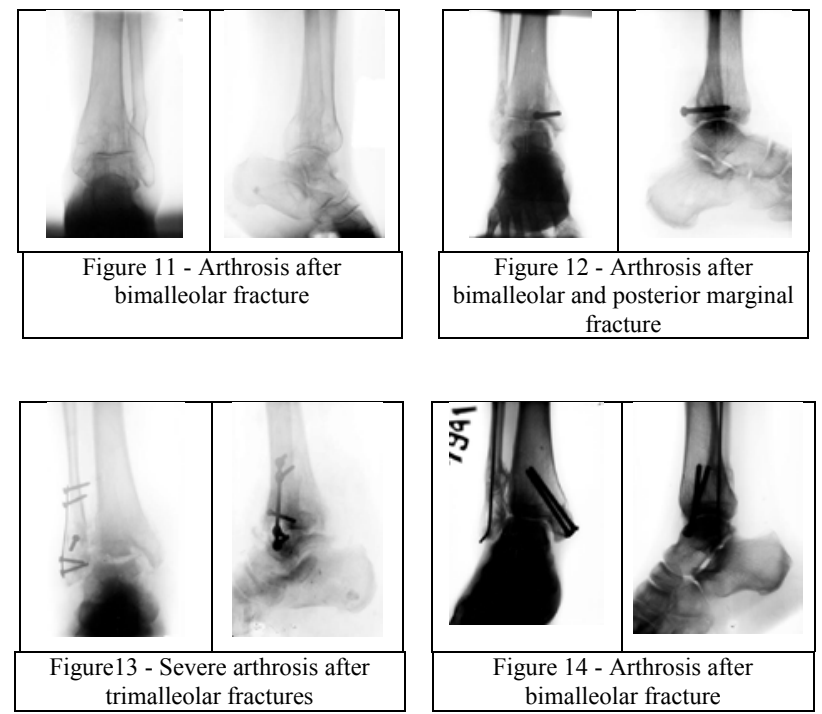

\section{Discussion}

A correct evaluation of the $\mathrm{x}$-rays permit not only to establish a complet lesional diagnosis, but also the evaluation of late complications with insidious clinical manifestations sometimes [6].

The radiological parameters show the continuity of articular surfaces, centration and parallelism of astragal in the ankle joint. Skinner test appreciate the congruency and decentration of astragalus, which suggest ligamentous lesions. External luxation, showed on x-rays by the internal tibio-astragalian diastasis, with tolerated value till 4 $\mathrm{mm}$, signifies internal ligamentous lesions associated to the peroneus malleolus fracture, and the presence of inferior tibio-peronier diastasis (empty space $5 \mathrm{~mm}$ ) signifies lesions of inferior tibio-peroneal ligaments [7]. 
In single fractures with displacement of peroneus malleolus should be suspected possible ligament damage, mentioned above, highlighted in radiological forced positions. Joint unilateral external may be following a fracture of the tibial pylon, and its association with decentred of astragalus and peroneus malleolus fracture is associated with ligament injuries. Peroneus malleolus is an element of joint stability that can be compromised by fracturing. Peroneus malleolus, measured movements based on radiological indexes, impose appropriate osteosynthesis techniques to ensure a perfect anatomical restoration and firm stability. A shortening of radiological peroneus malleolus by more than 2 $\mathrm{mm}$ is intolerable, leading to vicious consolidation, with arthrosis risk.

Any fracture movement of over $2 \mathrm{~mm}$, in either direction, is intolerable and anatomical reduction and stabilization requires. Radiographic measurement of "clear" tibio-peroneal space $(\mathrm{C}=$ $2 \mathrm{~mm}$ ) can give informations about the integrity of tibio-peroneal ligaments. Clear space over $5 \mathrm{~mm}$ expresses a ligamentary injury and joint instability. Tibio-peroneal diastasis or tibio-astragalian diastasis destabilize the joint, being arthrosic risk factors. Talus tilting on $\mathrm{x}$-ray profile pictures is tolerable up to $1.5^{\circ}$ (clinical, above this value, the indices have pathological significance).

According to the evaluation of these precise parameters, we can decide that only a surgical treatment correctly applied can achieve the anatomical and biomechanical recovery $[8,9]$. In the second group, there observed angle values under the normal value, after 12 bimalleolar fractures, 3 peroneus malleolus fractures with internal equivalence and 4 trimalleolar fractures, having as cause the vicious consolidation of peroneus malleolus. Internal tibioastragalian diastasis was reported after five peroneus malleolus fractures with internal equivalence (ligamentous lesions), after 3 bimalleolar fractures and 2 trimalleolar fractures. Internal diastasis means incorrectly or incomplete resolution of internal ligamentous lesions. The presence of tibio-peroneal diastasis prove retrospectively the incorrect resolution of the ligamentous lesions in this joint, reported after 5 bimalleolar lesions, 4 peroneus malleolus fractures with internal equivalency and 2 trimalleolar fractures.
Böhler consider that any displacement of astragalus, even a small one on X-ray, can be factor of arthrosis after a few years. Kapandji said, all the lesions of the ankle impose a perfect resolution, if it is wanted the recovery of the stability and of the function [10].

The above radiological parameters indicated an anatomical recovery in $60.9 \%$ of cases, although $9.19 \%$ already presented incipient lesions of arthrosis due to postinflamatory trophic disorders. In $25.28 \%$ of cases were found the elements of arthrosis risk due to late complications, and in $13.8 \%$ of cases with unfavorable evolution presented radiological signs of decentred arthrosis.

\section{Conclusions}

Joint instability increase with the complexity of the osteoligamentous injuries and with the starting of weight bearing and walk. Biomechanical conditions of the ankle impose an anatomical recovery of the osteoligamentous stability components compromised by the trauma. The surgical treatment can realize the anatomical restoration as perfect as possible. Due to early and late postsurgical evaluation, using the radiological tibio-astragalian parameters, we can find the sequelar articular imperfections

\section{References}

1. Brage M.E., Bennett Cr., White Hurst J.B., Getty P.J. \& Toledano A. (1997). Observer Reability in Ankle Radiographic Measurement. Foot Ankle Int. 18(6), 324-329

2. Libotte M., Klein P., Colpaerth, Alameh M., Blaimont P. \& Halleux P. (1982). Contribution a l'etude biomecanique de la prince malleolaire. 
Rev. Chir. Orthop. Paris, 68, 299-305

3. Ahl T., Dalen N., Lundberg A. \& Bylund C. (1993). Early Mobilization of Operated on Ankle Fractures. Prospective, Controlled Study of 40 Bimmalleolar Casses, Acta Orthop. Scand. 64(1), 95-99

4. Wangermez I., Bonjean P. \& Wangermez A. (1962). Mesure radiologique du diastazis tibioperonier inferieur. La Presse Medicale Paris. 70(40), 1858-1861

5. Lauge - Hansen N. (1954). Fractures of the Ankle III Genetic Roentgenologie Diagnostic of Fractures of the Ankle. J. Roentgenol. 71(3), 456-471
6. Georgescu N., Trandabăţ C. \& Cosma T. (1934). Examen radiologic în traumatismele gleznei, Rev. Ortop. Traum. 4(3-4), 178-179

7. Denischi A., Antonescu D. (1977). Gonartroza. (pp. 42). Bucureşti: Ed. Medicală

8. Beris A.E., Kabbani K.T., Mibionis G. \& Soucacos P.N. (1977). Surgical Treatment of Malleolar Fractures. A Review of 144 Patients, Cli. Orthop. 341, 90-98

9. Gorun N. (2000). Fracturi maleolare. (pp. 35, 8793, 98-99, 172). București: Ed. "Curtea Veche"

10. Kapandji I. (1970). Physiologie articulaires. fasc. II, 3 edition. (pp. 136-153). Paris: Libraire Maloine S.A. 